\title{
A disciplina de História no Paraná nos tempos do Império: indícios da formação do campo disciplinar
}

\section{The discipline of History in the state of Paraná during the Imperial era: traces of an imminent field of study}

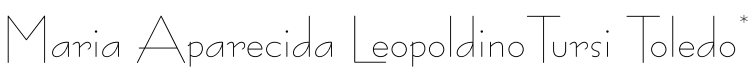

Introdução:

Siles disciplines scolaires sont le résultat d'une longue et complexe élaboration colective, d'un processus localisable et datable, et non la manifestation d'une Idée intemporalle, $[\ldots]^{1}$.

(Annie Bruter)

Em meados do século XIX, a história se firma como disciplina escolar no Paraná por intermédio do ensino secundário na capital da Província. Como em diferentes partes do país, tornou-se visível no cenário curitibano a presença de conteúdos históricos ligados ao surgimento da nação considerados imprescindiveis às elites locais diante da necessidade de legitimar um saber sobre o passado nacional.

Em meio às mudanças que ocorriam no país desde o seu processo de afirmação como corpo político autônomo em 1822 e a emancipação política da Província, ocorrida em

\footnotetext{
* Departamento de Teoria e Prática da Educação, Área de Didática e Metodologia do Ensino. UEM. E-mail: maria.leopoldino@hotmail.com

${ }^{1}$ BRUTER, Annie. L'Histoire Enseignée au Grand Siècle. Belin, 1997.
} 
1853, verificam-se, no decorrer das décadas de 1850/1870, os conhecimentos históricos se firmarem como saber escolar tendo em vista as chamadas "questões nacionais", com as quais as elites intelectuais do período se defrontavam no espaço paranaense.

Entre aquelas décadas, a afirmação do campo disciplinar da História escolar se realizou, na instituição de ensino secundário, por meio dos seguintes elementos: a presença da História nos exames de preparatórios; a sua afirmação como disciplina escolar autônoma da Geografia no Colégio Pedro II; o crescimento da necessidade de um saber histórico da Pátria, que culminou com a criação da cadeira de História do Brasil em 1849, no colégio oficial da Corte, e numa historiografia didática nacional; a paulatina configuração de um corpo professoral ligado a esses conteúdos, bem como as mudanças empreendidas pela historiografia em fins do século XIX e início do século XX.

Este trabalho trata dessa questão e, embora não pretenda abordar todos os elementos que concorreram para a formação do campo disciplinar da História no Paraná indicados anteriormente, observa que dois foram determinantes para a sua organização - no período que vai de 1858 a 1876 - e podem apontar indícios do processo que culminou na formação do campo disciplinar da História no Paraná: os exames de preparatórios e os compêndios adotados no Colégio Pedro II.

O texto, portanto, ao tratar da disciplina no espaço paranaense, retoma a questão que liga o seu nascimento com a construção do Estado-nacional. Nesse sentido, entende que embora o tema seja amplamente conhecido, a maneira como tal questão foi enfrentada ou as polêmicas que foram produzidas entre os agentes envolvidos com a afirmação da História como disciplina escolar nas diferentes provincias do Império brasileiro ainda permanecem por se conhecer. Por isso, considera importante retomar a temática deslocando-se no tempo e no espaço para compreender o trajeto de afirmação da disciplina na sua relação com as instituições de ensino e os poderes instituídos no período abordado.

Para o trato com a temática, as contribuições teóricas e metodológicas de André Chervel (1990; 1998)² e Ivor Goodson

${ }^{2}$ CHERVEL, André. "História das disciplinas escolares: reflexões sobre um campo de pes- 
$(1991 ; 1998)^{3}$, sobre a história das disciplinas escolares e da construção social do currículo, são consideradas para conceituar a expressão campo disciplinar presente neste trabalho.

Tanto para Chervel quanto para Goodson, as disciplinas escolares se formam no interior de uma "cultura escolar" que possui entidades epistemológicas relativamente autônomas quando relacionadas às chamadas "ciências de referência". Em seus estudos, os autores concebem a escola como uma instituição histórico-social que obedece a construções particulares e específicas das quais participam vários agentes - tanto internos quanto externos a ela - que compõe um "lugar social" de produção de saberes próprios, embora não contrários e nem estranhos aos conhecimentos "científicos".

$\mathrm{Na}$ perspectiva de ambos os autores, as disciplinas escolares devem ser entendidas como integrantes da "cultura escolar" para que se torne possível entender as relações que elas estabelecem com a conjuntura social de sua época. Serão esses laços relacionais que permitirão visualizar a formação e a afirmação de determinados saberes como disciplina escolar autônoma, ou seja, com campo de conhecimentos próprios. No trajeto de constituição de uma disciplina escolar, encontram-se, portanto, determinações político-culturais que explicam a seleção de conteúdos e suas finalidades sociais, das quais a escola participa direta ou indiretamente. Esses elementos conduzem, organizam e orientam a formação dos campos de domínio [saberes] de determinada disciplina que, por intermédio de conflitos e negociações com outras "áreas" de conhecimento, são partilhados no processo de formação do saber disciplinar que compõe, como se entende atualmente, um corpus curricular.

quisa". Teoria \& Educação. Porto Alegre, n.2, p.177, 1990. La culture scolaire: une approche historique. Paris: Éditions Belin, 1998.

${ }^{3}$ GOODSON. Ivor. "La construcción social del curriculum. Possibilidades y âmbitos de investigación de la historia del curriculum". Revista de Educación, Madri, vol.295, 1991. Historia del currículo - la construcion social de las disciplinas escolares. Barcelona: Ediciones Pomares-Corredor,., 1998.

${ }^{4}$ Segundo Chervel (1998), o conceito de cultura escolar se refere à existência de uma cultura especificamente escolar no contexto das relações sociais em que a instituição se insere. Trata-se de uma cultura que é, em princípio, engendrada no interior das práticas escolares por meio dos acordos pedagógicos "[...] ou plus étroitement didactiques qui accompagnent en permanence l'enseignement donné en milieu scolaire[...]" (p.7). 
Por essa abordagem, torna-se significativa a pesquisa empírica sobre as diferentes disciplinas para a compreensão do processo pelo qual cada uma delas se origina e instala nos currículos escolares. A contribuição do presente artigo reside justamente nesse aspecto, ou seja, procura pontuar alguns dos elementos históricos que concorreram para a afirmação da História como disciplina escolar no Paraná em meados do século XIX.

O lugar institucional: a organização dos conteúdos de História no Liceu de Curitiba e no Instituto de Preparatórios

Como ocorria em outras províncias brasileiras, o ensino secundário no Paraná, em meados do século XIX, se fazia por intermédio da instituição denominada Liceu e servia de instrumento na distribuição privilegiada de instrução à classe senhorial numa sociedade de economia agro-exportadora cuja base de produção econômica se fazia por intermédio do trabalho escravo.

Criado em 1846, pela Lei Paulista n.33, o Liceu de Curitiba foi instituído na recém-criada Província como parte de um conjunto de medidas tomadas pelos poderes locais visando organizar a instrução secundária local. A história dessa instituição, que se articula ao movimento de constituição e consolidação de uma educação voltada para a formação das elites intelectuais, tem uma trajetória marcada pela conjuntura sócio-cultural do Império, cuja política educacional empreendida pelas autoridades se revela no trajeto de contínua criação e extinção da instituição como Liceu. Ou seja, embora o Liceu de Curitiba estivesse projetado para ser um curso regular de humanidades, a se desenvolver em sete anos, a Politica dos Exames de Preparatórios determinava, no cenário nacional, a procura dos jovens estudantes por tais cursos.

Tal política dizia respeito ao espaço reservado para o curso secundário pelo Ato Adicional de 1834. Por sua prescrição, essa modalidade de ensino ficou dividida em dois sistemas paralelos que perduraram até o período republicano. O sistema regular, seriado, oferecido no Colégio Oficial da Corte - O Imperial Colégio de Pedro Segundo - e, eventualmente pelos Liceus 
Provinciais e alguns poucos estabelecimentos particulares; e o sistema irregular, de aulas avulsas ${ }^{5}$, mantido em sua maioria pelas instituições provinciais, constituídos pelos cursos de preparatórios e exames parcelados de ingresso ao ensino superior ${ }^{6}$.

Como parte de tal projeto político, o Liceu de Curitiba não conseguiu firmar-se em função da falta de alunos matriculados nas aulas. Isso porque a não exigência do título de bacharel - obtido na conclusão do ensino secundário regular - para a entrada nos cursos superiores provocava a busca dos candidatos pela aprovação direta nos exames promovidos pelo governo imperial. Essa prática era intensificada na medida em que não era possibilitado aos liceus provinciais darem entrada direta aos cursos superiores sem prestar os exames gerais ${ }^{7}$. A grande predominância dos exames de preparatórios sobre o ensino gradual, fortalecida pelas próprias normas que regulamentavam o ingresso nos cursos superiores do Império, determinou a substituição do Liceu de Curitiba pelo Instituto de Preparatórios em 1876.

Por outro lado, o Colégio Pedro II, ao centralizar as decisões político-pedagógicas, passou a ser o modelo do curso secundário para as Provincias, uma vez que as autoridades locais, pensando nos exames de preparatórios, buscavam solucionar o problema procurando meios para oferecer as aulas exigidas e organizadas tal como o Colégio Oficial da Corte. Dessa maneira, foram os exames de preparatórios e as indicações do Colégio Pedro II que, orientando as ações das autoridades locais, concorreram para a legitimação do saber histórico escolar nas provincias brasileiras.

Em meio à intensificação da política que caracterizava o ensino secundário da época, se observa a afirmação da disciplina na instituição paranaense a partir de 1858. Seguindo o livro de atas de exames do Liceu, de 1858 a 1861, a instituição ofereceu as seguintes aulas avulsas de História: História

\footnotetext{
${ }^{5}$ As aulas correspondiam aos conteúdos que eram oferecidos por meio da cadeira para os fins dos exames.

${ }^{6}$ HAIDAR, Maria de L.M. O ensino secundário no Império Brasileiro. São Paulo: EDUSP/ Grijalbo 1972, p.47 a 80.

${ }^{7}$ PILETTI, Nelson. "Evolução do currículo do curso secundário no Brasil". Revista da Faculdade de Educação. São Paulo, n.13, jul/dez. 1987, p.35.
} 
Sagrada, no velho testamento $\left(1858-5^{a}\right.$ classe); História Sagrada, no novo testamento e História Universal e Antiga (1859 - $4^{a}$ classe); História Sagrada, novo testamento; História Universal e Antiga (1860 - $4^{a}$ classe); Geografia e Historia $\left(1861-3^{a} \text { classe }\right)^{8}$. Essa composição, definida em função dos Exames, indicou os primeiros movimentos em torno da organização dos conteúdos disciplinares da História no Paraná.

A presença da História Sagrada, oferecida nas classes iniciais do curso, pode ser compreendida considerando que no cenário político-cultural brasileiro de meados do século XIX, a Igreja, dada a antiga presença da ordem católica no país - fazendo jus a beneficios institucionais e financeiros -, interferia no relacionamento Igreja-Estado e defendia as prerrogativas eclesiásticas com sua forte presença na educação das elites letradas.

A esse aspecto político-cultural, soma-se a tradição do ensino de humanidades em que a historiografia estava submersa. Ou seja, o universo mental cristão enquadrava a representação do mundo para a veneração do divino, a celebração dos dogmas cristãos e a evangelização, conforme observou Tétart apoiado nas análises de Henri-Irénée Marrou: “[...] a Bíblia, a história do povo eleito, o ensinamento da escritura e a historiografia que se segue inscrevem-se no desenvolvimento da humanidade. [...] a historia escrita pelos cristãos é, em si, um fator de inteligibilidade do mundo" 9 .

É nesse sentido que se pode explicar, inclusive, a presença da Historia Universal e Antiga entre os "pontos" que os candidatos aos exames deveriam mostrar conhecer nos idos de 1850. Considerada fator de inteligibilidade do "mundo", a história cristã inscreve-se na lógica providencialista, limitando a lógica factual ao efeito da vontade divina. Dessa forma, sua inclinação para uma história universalista permitia que, no avanço das classes no Liceu, a antiguidade fosse contemplada, ainda que sob a égide da perspectiva cristã já no segundo ano do curso - na $4^{\text {a }}$ classe.

${ }^{8}$ TOLEDO, Maria A. Leopoldino T. A disciplina de História no Paraná: os compêndios de História e a história ensinada (1876-1905). Tese de Doutorado. Programa de Pós-Graduação em Educação. Pontifícia Universidade Católica de São Paulo, 2005.

${ }^{9}$ TÉTART, P. Pequena história dos historiadores. Tradução Maria Leonor Loureiro. Bauru, SP: EDUSC, 2000, p. 34. 
A história universal e evangelizadora, no entanto, terá seu espaço diminuído a partir da década de 1860. A prescrição que aparece em 1861 para as classes finais - Geografia e Historia indicava os novos contornos políticos e pedagógicos que a disciplina assumia frente às mudanças que se processavam na vida social brasileira.

De acordo com Miceli, ao longo do periodo imperial, sucessivas medidas legais buscavam estancar a presença da Igreja nos atos políticos nacionais, sendo que uma das estratégias foi intervir no recrutamento de quadros para as ordens religiosas e para o exercício da docência, conforme segue:

À proibição de admissão de noviços pelas ordens religiosas (1855) seguem-se um amplo regime de inspeção pública dos seminários seculares (1863) e a proibição de ingressos no país aos noviços brasileiros ordenados no exterior (1870). Durante quase um século não houve sequer fundação de seminário no país. Afora o estrito controle que intentava exercer sobre o conteúdo das disciplinas e compêndios utilizados nas casas de formação, o governo contribuira ainda para subtrair os docentes ao controle episcopal ao convertê-los em "professores externos" cujos proventos estavam assegurados em orçamento ${ }^{10}$.

O cerceamento governamental - respondido com ações legais pelo clero brasileiro - indicava as tendências de fortalecimento da política de "estadualização" empreendida pelos poderes que implementavam projetos de "Estados nacionais modernos". Nesse trajeto, no decorrer da década de 1860, a história que se ensinava na instituição paranaense encaminhava-se para a laicização de seus conteúdos.

De 1861 a 1876, o Liceu de Curitiba não conseguiu se definir como um curso regular. Os jovens aspirantes aos cursos superiores logo abandonavam a Província para se dirigirem à Corte ou São Paulo, conforme observava o presidente da Província à época:

As esperanças depositadas pela prosperidade do Liceu não tem correspondido àfrequência que se nota. [...]. A retirada de alguns alunos para a Côrte e São Paulo onde se vão preparar para os estudos superiores confirma a minha posição. [...]. Os moços

\footnotetext{
${ }^{10}$ MICELI, Sergio. A elite eclesiástica brasileira: 1890-1930. Rio de Janeiro: Bertrand Brasil, 2009 , p. 22.
} 
preferem fazer estudos preparatórios com os professores que mais tarde tem de julgar, ganhando assim a vantagem de se habilitar no método de ensino de cada um deles ${ }^{11}$.

A falta de alunos e de provimentos necessários ao funcionamento regular do Liceu conduziu à extinção do curso na forma como se apresentava, reafirmando a centralização do ensino secundário no Colégio Oficial da Corte com a criação do Instituto de Preparatórios em 1876.

Em 1876, o ensino da mocidade paranaense se fazia por intermédio do Instituto que, por força das mudanças que se processavam na politica local, passou a manter uma Escola Normal anexo ${ }^{12}$. Sua afirmação como um "estabelecimento publico de linguas e sciencias preparatórias" ${ }^{13}$ liga-se, basicamente, ao intento das autoridades locais de oferecer as matérias exigidas nos Exames Parcelados.

No processo de criar novas cadeiras ${ }^{14}$ para que o Instituto de Preparatórios mantivesse o número de aulas exigidas pelos exames parcelados, é que se verifica a História firmando seu espaço nos programas da instituição como disciplina laica, no lastro da política de equiparação ao Colégio Pedro II. Em meio à intensificação da política que caracterizava os cursos secundários em todo o país, a cadeira de História Universal se consolida em 1876 na capital paranaense.

A presença das aulas de História Universal, como previa o Regulamento de 1876, mostra que o conteúdo da história escolar estava prescrito para ser ensinado separado da Geografia e, ao mesmo tempo, que a História do Brasil não aparece como disciplina autônoma. Sobre essa prescrição explicava o então presidente da Provincia, Lamenha Lins, à época: “[...] se é obra imperfeita, não deixa, todavia, de acompanhar os progressos os

${ }^{11}$ PARANÁ. Relatório do presidente da província Sr. José Francisco Cardoso da Costa. $1^{\circ}$ de Março de 1860, p.22.

${ }^{12}$ Para mais informações sobre o assunto, ver: TOLEDO. Maria A. Leopoldino Tursi, op. cit. ${ }^{13}$ PARANÁ. "Regulamento de 16 de julho de 1876". In: Coleção de Leis e Decretos da Provincia do Parana 1875-1876. Curityba:Typographia Perseverança, 1876.

${ }^{14} \mathrm{O}$ termo cadeira era utilizado para designar uma especialidade dos estudos a ser ministrada pelo respectivo professor - o catedrático. (GASPARELO, Arlette M. Construtores de identidades: a pedagogia da nação nos livros didáticos da escola secundária brasileira. São Paulo: Iglu, 2004, p.68). 
mais realizaveis em materia de ensino"15. Acompanhar os progressos do ensino no período era, por sua vez, seguir as determinações do Colégio Pedro II.

No Programa de 1877 do Colégio da Corte - organizado pelo Decreto Imperial de $1^{\circ}$ de Março de 1876 -, a cadeira de História aparece separada da Geografia com a denominação de História Universal e assim dividida: História Antiga e Média ( $4^{\circ}$ ano); História Moderna e Contemporânea ( $5^{\circ}$ ano); História do Brasil $\left(7^{\circ} \text { ano }\right)^{16}$.

No curso de humanidades oferecido pelo Colégio Oficial, a história se consolida como disciplina autônoma da Geografia. $\mathrm{Na}$ instituição paranaense, no entanto, embora estivesse indicada no Regulamento de 1876 para ser independente da Geografia, pelas indicações do livro de posse dos lentes e professores do Instituto, elas aparecem unidas.

João Pereira Lagos Junior esteve à frente da cadeira em 1876, a qual está denominada de História Universal e Geografia e Cosmographia. Além disso, a partir de 1877, sob a responsabilidade de Previsto Gonçalves Columbia, a cadeira passava a oferecer também a História do Brasil ${ }^{17}$. Por essa composição, as aulas de História Universal, sob a responsabilidade de um professor, congregavam os conteúdos de História, Geografia e Cosmografia necessários aos exames.

A explicação para tal composição, para além da indicação das dificuldades com a falta de professores interessados nos conteúdos da cadeira, era que, no Paraná, o ensino de História se configurava em meio à intensificação da dualidade que caracterizava o ensino secundário local: a intenção das autoridades em criar um curso regular de humanidades, mas, ao mesmo tempo, oferecer aulas avulsas das matérias exigidas nos exames de preparatórios. Diante das dificuldades em manter as classes de forma regular, a solução encontrada foi unir as matérias na cadeira de História Universal.

\footnotetext{
${ }^{15}$ Relatório de presidente da Província Lamenha Lins, de 15 de fevereiro de 1877. In.: MOACYR, Primitivo. A instrução e as províncias (1834-1889). São Paulo: Ed. Nacional, 1940, p. 298.

${ }^{16}$ VECHIA, Ariclê. (Org.). Programas de ensino da escola secundária brasileira: 1850-1951. Curitiba: Editora do Autor, 1998, p.32.

${ }^{17}$ Conforme TOLEDO, op. cit.
} 
Essa situação, no entanto, não impediu que a disciplina fosse delineando seus conteúdos na instituição. Se a política dos exames preparatórios contribuiu para sua legitimação como matéria necessária nas províncias, o Colégio Pedro II foi determinante para a configuração do quê e como ensinar por intermédio dos livros que adotou.

A composição dos conteúdos foi definida, nessa fase, por dois compêndios que, presentes no Colégio Oficial, foram indicados para ser adotados no Instituto em $1870^{18}$ e 1882 respectivamente: História Universal, do francês Victor Duruy, traduzido com adaptações para o ensino brasileiro; e Lições de História do Brasil - para os alunos do Colégio Pedro II, de Joaquim Manoel de Macedo.

A cadeira de História Universal compondo-se daqueles períodos históricos mencionados (Antiga e Média; Moderna e Contemporânea) e incluindo a História do Brasil - relacionada com os compêndios indicados para prover as aulas - dá indícios da organização dos conteúdos que foram selecionados em decorrência dos embates políticos e sociais realizados em torno do país independente na década de 1870 .

Nos idos daquela década e das subsequentes, a necessidade de se estabelecer políticas de manutenção da unidade interna do país não estava encerrada posto que os conflitos e as ameaças de rompimento da unidade nacional permaneceram por todo o período imperial. Não é, pois, dificil identificar que nos conteúdos desse ensino - fundamentalmente para o curso secundário -, a busca por principios balizadores da ordem e da civilização deveria enfrentar os problemas de amortizar um passado recente coberto por muitos conflitos como foi o caso da independência brasileira. Por isso a escolha se deu por conteúdos que pudessem unificar, na narrativa, o passado histórico da nação.

Por meio das duas obras referidas, a disciplina de História no Paraná, inserida no conjunto enciclopédico e universal de conhecimentos sobre o passado, foi se definindo, a partir desse

\footnotetext{
${ }^{18}$ Citado no ofício da Tesouraria Provincial do Paraná (Ofício n.89 de 24 de março de 1870) endereçado ao Presidente da Província, Antonio Luiz Affonso de Carvalho, para a compra a ser realizada, entre outros livros, na Corte. Nele, o registro da obra está assim anunciado: compra do "Compêndio de História Universal" de Victor Duruy (PARANÁ, Correspondência de Governo, AP.331, vol.08, 1870, p.132).
} 
período, em função de uma historiografia didática que se caracterizou por relacionar duas frentes de saberes que se relacionavam mutuamente no ensino secundário: um saber Universal e um Nacional.

\section{Os compêndios como ordenadores do saber escolar no Império Brasileiro: a história entre o Universal e o Nacional}

A legitimação da cadeira de História Universal, criada com o regulamento de 1876 na capital da Província, vinculou-se à procura dos candidatos aos exames e, na composição de seus conteúdos, à adoção das duas obras didáticas referidas.

Pensados num momento em que as finalidades educacionais estavam definidas pelas intenções de se fazer uma História adequada aos princípios políticos do Império, tais compêndios serviram de sustentáculo para se pensar, no Instituto de Preparatórios, os caminhos para o desenvolvimento da nacionalidade brasileira no período imperial.

Produzido no cenário francês, o compêndio Histoire Universelle, publicado pela Librairie Hachette ( $1^{a}$ edição em 1855) para uma "sociedade de professores e de especialistas", é o resultado das histórias escritas por Duruy, em períodos anteriores, sobre Roma, o período chamado Antigo Regime, o período moderno e a História da França ${ }^{19}$. Obra considerada inovadora na ocasião, trata de acontecimentos de uma história política que procura as marcas iniciais dos povos em sua "evolução" na terra e suas formas de organização social, representando o pensamento de seu autor sobre os fins pedagógicos do ensino da História.

Nascido em Paris aos 11 de setembro de 1811, Victor Duruy teve uma vida norteada pelos debates em torno da constituição da Escola Pública na França. Foi Inspetor Geral do Ensino Secundário e publicou vários livros de História; foi Ministro da Instrução Pública de 1863 a 1869, foi senador em 1869. Membro do Conselho Superior de Instrução Pública de 1881 a 1886 e da Academia das Inscriptions em 1873.

\footnotetext{
19 ACADEMIE FRANCAISE, Victor Duruy. <http://www.academie-francaise.fr/actualites/actu_2004.asp 2004>. Acesso em: 18 nov. 2004.
} 
Participou da Academia de Ciências Morais e Politicas em 1879 e, em 4 de dezembro de 1884, da Academia Francesa, entre outras designações exercidas até sua morte em 25 de novembro de $1894^{20}$.

Diretamente interessado no debate sobre a História como disciplina escolar nas propostas de laicização do ensino público, que empreendeu naquele país ${ }^{21}$, suas obras expressam a vivência política de um período em que o projeto de constituição da escola pública laica se confrontava com os poderes religiosos na França ${ }^{22}$. Exatamente por isso, ao ser traduzido para as circunstâncias brasileiras, o repertório europeu é redefinido.

O compêndio do autor francês foi traduzido e adaptado, em 1865 , pelo clérigo Francisco Bernardino de Souza. Segundo Bitencourt, a intervenção do tradutor foi responsável por algumas alterações importantes na obra. Houve, por exemplo, uma redefinição dos capítulos iniciais do livro. O tradutor, "procurando acentuar a origem sagrada do homem", modificou a lógica do compêndio. Observa Bittencourt:

No original, [...] Duruy buscou apresentar uma configuração geral dos continentes e as formas de comunicação estabelecidas entre os diferentes povos. No capítulo II,[...], o autor apresentava as tradições bíblicas sobre os primeiros homens para explicar que as 3 raças humanas estavam presentes na versão religiosa católica, $[\ldots]$. .O tradutor brasileiro inverteu a apresentação dos capitulos. Iniciou o livro com o Tempos primitivos - Tradições bíblicas - fundação dos impérios e no final incluiu, resumidamente os limites do mundo conhecido pelos antigos. A inversão dos temas, $[\ldots]$ indicou um reforço quanto à versão cristã da história do homem, interpretação que Duruy atenuou ao enxertar os pareceres científicos quanto à origem das raças humanas ${ }^{23}$.

\footnotetext{
${ }^{20}$ Idem.

${ }^{21}$ HERY, Evelyne. "Les enjeux de l'enseignement de l’histoire (1880-1902)". In.: Un siècle de leçons d'histoire - $1^{\prime}$ histoire enseignée au lycée, 1870-1970. Presses Universitaires de Rennes, 1999; PONTEIL, Felix. "Les tribulations de l'universite la lente reprise du pouvoir civil de Rouland a Victor Duruy". In.: PONTEIL, Felix. Histoire de enseignement en France - Les grandes étapes (1789-1964). Paris: Sirey, 1966.

${ }^{22}$ PONTEIL, op. cit.

${ }^{23}$ BITTENCOURT, Circe Maria. Livro didático e conhecimento histórico: uma história do saber escolar. 1993. 234f. Tese (Doutorado em Educação). Faculdade de Educação, Universidade de São Paulo, 1993.
} 
Além disso, constata a autora que houve omissões de alguns subitens e acréscimos de conteúdos. Na tradução ocorre a inclusão de um capítulo sobre a história de Portugal no final da Idade Média e outro sobre o reino português durante o período da História Moderna, desde o reinado de D.João II até o de D. Pedro V. Essas intervenções feitas pelo clérigo - então professor do Colégio Pedro II - são significativas para apontar o vínculo que se estabeleceu entre as produções historiográficas escolares e o cenário político-cultural do país que circundavam a geração de letrados na década de 1870 .

No campo educacional, a preocupação com os caminhos que a sociedade brasileira poderia tomar frente aos acontecimentos vividos após as crises regenciais e no segundo reinado conduziu parte das elites intelectuais a repensar a unidade da nação. Nesse sentido, pode-se entender a construção da narrativa para explicar, na tradução da obra francesa, o surgimento da nação brasileira no quadro das "nações modernas".

$\mathrm{Na}$ historia universal do autor francês, a História está dividia nas etapas: Antiga, Idade Média e Historia dos Tempos Modernos. O trajeto civilizador é narrado tomando-se inicialmente Roma. As lutas travadas na antiguidade são vistas como importante condutor da organização política e social. A "Fundação da República Romana" (item 11 da obra) é contada pelo viés dos grandes imperadores (Cesar, Augusto) que são enaltecidos pela administração do poder público. Na Idade Média, enfatiza os "Principais Estados fundados pelos bárbaros no império romano, nos séculos V e VI" (item 02). Nesse período, inicia-se o estudo da França em seu "desdobramento em grandes feudos" (item 07) e constituição como uma das "grandes nações modernas" (item 10) ${ }^{24}$. Esses excertos da obra dão o tom da narrativa de Duruy e sinalizam para a justificativa de sua tradução e uso nas instituições de ensino secundário no Brasil na época do Império. Ou seja, ela teve como fio condutor uma narrativa que elaborava uma imagem que consolidasse o Brasil como símbolo de unidade, parte integrante da cultura ocidental civilizada narrada por Duruy.

${ }^{24}$ DURUY, Victor. Compendio da historia universal. Tradução Francisco Bernardino de Souza. 3. ed. Rio de Janeiro: Livraria Garnier, 1873. 
A imagem das grandes nações estudadas em seu processo de formação nas páginas da História Universal é consolidada por Joaquim Manoel de Macedo para explicar o caso brasileiro. Com seu compêndio, elabora-se um modelo de História nacional que se vincula ao trajeto universal de formação dos Estadosnacionais europeus. Escrito em 1861 e adotado no Colégio da Corte nesse momento, Macedo afirma o seguinte ao narrar os fatos que marcaram, na sua leitura, a construção do país como nação independente:

Ha mais de trezseculos que teve lugar o descobrimento do Brazil, ha perto de meio seculo que a terra da Santa Cruz regenerou-se e escreveo o seo nome na lista das nações do mundo e suas variadas fontes de riqueza, e seos numerosos produtos naturaes não estão ainda reconhecidos e explorados, e menos ainda aproveitados, senão em uma parte, que pouco a pouco se vai engrandecendo, e que mal deixa calcular o todo dos prodigiosos thesouros, que Deos semeou nella com mão bemfazeja e prodiga $^{25}$.

Os conteúdos das Lições visavam não simplesmente à atmosfera educacional, como o autor escrevia, mas a sociedade imperial em que eram produzidos. Isso porque, conforme já indicaram outros autores que o estudaram ${ }^{26}$, Macedo materializa no conjunto de lições que escreve sua maneira de informar o passado a uma coletividade como parte de seu próprio esforço de construção identitária da nacionalidade brasileira. $\mathrm{O}$ entendimento de que se fazia necessário um compêndio que ensinasse aos jovens os momentos considerados mais importantes da História da Pátria indicou a importância de sua obra no intento de consolidar o projeto de unidade nacional via educação escolar.

\footnotetext{
${ }^{25}$ MACEDO, Joaquim. M. de. Lições de Historia do Brazil para uso dos alumnos do Imperial Collegio de Pedro Segundo. Rio de Janeiro: Typoographia Jose Gomes Brandao, 1861, p. 57.

${ }^{26}$ BITTENCOURT, Circe. M. Livro didático e conhecimento histórico: uma história do saber escolar. 1993. 234f. Tese de Doutorado em Educação. Faculdade de Educação, Universidade de São Paulo, 1993, p.176; MATTOS. Selma R. O Brasil em lições: a história como disciplina escolar em Joaquim Manoel de Macedo. Rio de Janeiro: Acces, 2000; GASPARELO, Arlette M. Construtores de identidades: a pedagogia da nação nos livros didáticos da escola secundária brasileira. São Paulo: Iglu, 2004.
} 
Adotado no Paraná em 1882, conforme a Ata do Conselho Literário do Instituto e Escola $\mathrm{Normal}^{27}$, sua indicação - quase duas décadas após ter sido adotado no Colégio da Corte - é representativa dos dilemas que a história nacional assumiu na Província frente à cadeira de História Universal que instituiu a disciplina em 1876.

Na década de 1870, a disciplina, embora organizada em seus conteúdos por meio da composição da cadeira que previa a História do Brasil, pela mediação do compêndio traduzido do francês, enfatizou o conteúdo Universal e a perspectiva cronológica presente no compêndio de Duruy.

Ao declarar a necessidade de se constituir uma nacionalidade, as gerações de intelectuais paranaenses das décadas de 1870-1880 construíram, pela interferência dos recursos literários disponiveis e os que iam buscar na corte imperial e fora do país, formas de abordagens a partir das quais passaram a pensar a sociedade de fins do Império e a si mesmos. Essa experiência político-cultural se definiu, no programa escolar para o ensino de História, por meio de duas balizas interpretativas: a experiência sócio-política local e nacional e o modelo civilizatório europeu.

As marcas definidoras da formação geopolítica dos espaços europeus e do desenvolvimento material e científico da humanidade, indicadas por Duruy, serviram para a elite letrada paranaense responder questões como:"o que é ser uma nação?”; "como se transforma uma população, um conjunto de pessoas agrupadas num espaço territorial, em nacionais?"; "Como se opera a transformação de uma população em um povo com um conjunto de valores e tradições comuns, ou seja, com uma identidade nacional?"

Nesse momento, na instituição paranaense, o Brasil, explicado na concepção de uma genealogia europeia a partir da época moderna, ficava, na representação coletiva da elite que cursava as aulas da cadeira de História Universal, ligado ao movimento da formação dos estados europeus e a uma historiografia francesa responsável pela laicização da proposta de ensino escolar.

${ }^{27}$ PARANÁ. Actas da Congregacao do Instituto e Escola Normal. Arquivo do Colégio Estadual do Paraná. Livro de Actas (1876-1889), Curitiba, [18-?]. 
Dessas observações, verifica-se que foi por meio dos conteúdos dos compêndios selecionados que o campo disciplinar da História escolar se definiu na instituição paranaense entre um saber universal e um nacional. Eles ajudaram a organizar inclusive os "Programas de Ensino" que, nesse momento, eram questionados em relação ao seu propósito de orientar a organização de cursos regulares, mas também de ser referência para a oferta das aulas que as instituições deveriam prover para os exames de preparatórios.

\section{Considerações Finais}

No processo de afirmação do país independente, quando as chamadas "questões nacionais" aparecem nos conteúdos escolares por meio do ensino do passado, é que se verifica a legitimação da História como disciplina escolar autônoma no Paraná.

Neste trabalho, preocupado em reconhecer os elementos que contribuíram para a afirmação do campo disciplinar dessa matéria no espaço paranaense, apresentou-se a Política dos Exames de Preparatórios e o Colégio Oficial da Corte - Pedro II como elementos determinantes no cenário do Império brasileiro.

Nesse sentido, ao apresentar o trajeto de afirmação da disciplina, enfatizou-se a predominância dos exames de preparatórios sobre o ensino gradual na instituição que nasce, em 1846, como Liceu de Curitiba. Tal política, fortalecida pelas próprias normas que regulamentavam o ingresso nos cursos superiores do Império, determinou a substituição do Liceu pelo Instituto de Preparatórios em 1876. Essa mudança deu continuidade ao processo de laicização dos saberes históricos escolares que ocorria em 1861com a alteração de conteúdos na cadeira de História do Liceu em 1858.

Com a criação do Instituto de Preparatórios, a disciplina firma-se como saber necessário para o conhecimento das nações europeias. A partir de 1876, é possivel verificar como o seu trajeto na instituição seguiu as determinações do Colégio Pedro II por intermédio da adoção de compêndios que foram referência na corte: História Universal, do francês Victor Duruy, traduzido com adaptações para o ensino brasileiro; e Lições de História do 
Brasil - para os alunos do Colégio Pedro II, de Joaquim Manoel de Macedo.

$\mathrm{Na}$ análise realizada, constatou-se que a opção por essas obras se ligou, do ponto de vista da produção historiográfica, às circunstâncias sociais brasileiras de meados do século XIX. Ou seja, ao se declarar, após o processo de afirmação do país como corpo político autônomo, a necessidade de se constituir uma nacionalidade, ao ensino de História coube conjugar uma narrativa que incorporasse um saber do passado nacional na perspectiva da História Universal. A tradução da obra francesa garantiu tal objetivo com as adaptações realizadas.

No seu processo de formação no Paraná, década de 1870, a disciplina foi organizada em seus conteúdos por mediação desses dois compêndios que, relacionando História Universal e Nacional, marcaram a atuação dos professores do periodo na capital da Provincia, porém com ênfase no conteúdo da História Universal. Nesse trajeto, o Colégio Pedro II e os compêndios escolares escolhidos para as cadeiras foram compreendidos como um dos elementos definidores do campo disciplinar da História escolar no cenário nacional.

Observados em sua ação formativa, os compêndios adotados governaram tenazmente a distribuição da autoridade dos conteúdos, as formas de ensino, a dignidade ou a marginalidade dos temas a serem ensinados à elite imperial. Nesse contexto, verificou-se que a dimensão universal do conhecimento histórico ganhou sentido para explicar, no Paraná, o cenário nacional, inscrevendo a narrativa do passado como parte dos desafios e questões com as quais as elites locais se debatiam em fins do século XIX. Postos em ação por interposição das escolhas e produções didático-pedagógicas de autores nacionais ligados ao colégio modelo, os compêndios responderam de forma muito específica aos desafios que envolviam as chamadas "questões nacionais" no Império brasileiro: a forma escolar.

A educação escolar, em seu processo de divulgação e recriação de saberes e prática culturais, tornou-se, conforme apontou Anderson ${ }^{28}$, fundamental na construção do imaginário sobre a nação. Os compêndios adotados estavam inscritos no processo de escolarização da disciplina e contribuíram,

${ }^{28}$ ANDERSON, Benedict. Nação e consciência nacional. São Paulo: Ática, 1989. 
em sua narrativa e expressão pedagógica, na construção das identidades nacionais. Foi dessa maneira que a construção do campo disciplinar da História percorreu os caminhos da formação da Nação brasileira, ensinando às elites como pensar o passado nacional.

Resumo: O artigo trata da história do ensino de História no Paraná em meados do século XIX. Por intermédio da história da disciplina, procura traçar o trajeto de afirmação do seu campo disciplinar ocorrido no Instituto de Preparatórios a partir da década de 1870. Toma como fonte para a análise dois compêndios adotados na instituição paranaense de ensino secundário e apresenta alguns dos elementos formadores dos conteúdos a serem ensinados. A análise tem por objetivo indicar como se tornou visível, no Paraná, a presença de conteúdos históricos ligados ao surgimento da nação num momento em que as elites locais se defrontavam com as chamadas "questões nacionais" no cenário do Império brasileiro.

Palavras-chave: Ensino de História. Paraná. Históriadadisciplina.

Abstract: The present article deals with the history of History teaching in the state of Parana in the mid-19th century. It seeks to trace, through the history of this discipline, the trajectory of affirmation of its field of study, which took place from the 1870s onwards at the Instituto de Preparatórios, a public secondary education institution. Our work is based on the analysis of two textbooks adopted in this institution and presents some of the elements that helped forming the content to be taught. The analysis aims to point out the visibility, in Paraná, of contents related to the historical birth of the nation, at a time when local elites were faced with the so-called "national questions" in the backdrop of the Brazilian Empire.

Keywords: History teaching. Paraná. History of the discipline.

Artigo recebido em: 23/11/2011

Artigo aprovado para publicação em:20/04/2012 